\title{
Psicologia da Religião e Psicologia Anomalística: aproximações pela produção recente
}

\author{
Anomalistic psychology and the psychology of \\ religion: connections by the recent production
}

\section{Wellington Zangari ${ }^{[a]}$, Fatima Regina Machado ${ }^{[a, b]}$, Everton de Oliveira Maraldi ${ }^{[a]}$, Leonardo Breno Martin ${ }^{[\mathrm{a}]^{*}}$}

[a] Universidade de São Paulo (USP), São Paulo, Brasil

[b] Pontifícia Universidade Católica (PUCSP), São Paulo, Brasil

\section{Resumo}

Este artigo tem como objetivo apresentar, de modo conciso, uma visão geral da produção em Psicologia da Religião oriunda de estudos da Psicologia Anomalística. Essa produção está aumentando uma vez que estudos acadêmicos estão sendo estimulados especialmente devido à criação/consolidação de alguns centros de pesquisa nos

* WZ: Doutor em Psicologia, e-mail: w.z@usp.br FRM: Doutora em Psicologia, e-mail: fatimaregina@usp.br EOM: Doutor em Psicologia, e-mail: evertonom@usp.br LBM: Doutor em Psicologia, e-mail: leobremartins@usp.br 
últimos anos. É feita uma breve introdução à Psicologia Anomalística em contraste com a Parapsicologia, remontando suas origens à Pesquisa Psíquica, antecessora da Parapsicologia. Posicionamentos "paranormófilos" e "paranormofóbicos" - posições extremas sobre a existência/inexistência de processos psicológicos heterodoxos são contrastados revelando um conflito entre perspectivas epistemológicas nas quais os papéis de religiosidade e da irreligiosidade parecem ser fundamentais. A relação entre experiências anômalas e religiosas é discutida com base em recentes estudos brasileiros na área da Psicologia Anomalística sobre experiências anômalas de tipo extrassensorial e extramotor, mediunidade, experiências de suposto contato com alienígenas, experiências fora-do-corpo e crenças paranormais. Estudos de Psicologia Anomalística realizados no Brasil indicam a sua imbricação e contribuição para o campo da Psicologia da Religião, especialmente devido à observada ligação íntima entre experiências anômalas e religiosas e a natureza aparentemente comum de seus objetos de estudo. Essas contribuições são importantes para a compreensão tanto das experiências religiosas quanto das experiências anômalas.

Palavras-chave: Psicologia Anomalística. Psicologia da Religião. Religiosidade. Experiências anômalas. Crenças paranormais.

\section{Abstract}

This article aims to present concisely an overview of the production in the Psychology of Religion coming from the Anomalistic Psychology studies. This production is increasing once their academic studies are being stimulated especially due to the creation/consolidation of some research centers in recent years. Anomalistic Psychology is briefly introduced in contrast to Parapsychology, being their origins traced back to Psychical Research, Parapsychology's predecessor. "Paranormophilic" and "paranormophobic" positions - extreme positions on the existence/nonexistence of heterodox psychological processes - are contrasted revealing a conflict between epistemological perspectives in which the roles of religiosity and irreligiosity seem to be fundamental. The relationship between anomalous and religious experiences is discussed based on recent Brazilian Anomalistic Psychology studies on extrasensory and extramotor anomalous experiences, mediumship, experiences of alleged contact with aliens, out-of-body experiences and paranormal beliefs. Anomalistic Psychology studies conducted in Brazil indicate its imbrication and contribution to field of the Psychology of Religion, 
especially due to the intimate alleged connection between anomalous and religious experiences and the apparently common nature of their objects of study. Such contributions are important to the understanding of religious and anomalous experiences.

Keywords: Anomalistic Psychology. Psychology of Religion. Religiosity. Anomalous experiences. Paranormal belief.

\section{Introdução}

Este texto tem como finalidade apresentar, de modo sucinto, um panorama da produção em Psicologia da Religião oriunda de estudos da Psicologia Anomalística. Tal produção tem crescido nos últimos anos posto que houve o estímulo aos estudos dessa área em nível acadêmico, dada a criação de alguns centros de pesquisa pelo país, como será apresentado abaixo. Antes, porém, de apresentar essa produção, faz-se necessária uma rápida introdução à Psicologia Anomalística, uma vez que ainda é pouco conhecida em nosso contexto.

Em fins da década de 1970 e início da década de 1980, a Psicologia Anomalística nasceu com uma perspectiva extremamente cética frente às alegações de ocorrências de eventos paranormais, buscando por mecanismos ou processos psicológicos por trás delas, distando, portanto, da Parapsicologia, que, por outro lado, tem como objetivo principal a avaliação ontológica de processos efetivamente paranormais. Vale salientar que aqui nos remetemos, especificamente, à Parapsicologia enquanto área de estudo científico que tem um lugar estabelecido na comunidade científica/acadêmica internacional (e não a eventuais deturpações que tal disciplina tenha sofrido no Brasil). Sob essa mesma denominação, em nosso país, encontramos linhas de pensamento esotérico e religioso que se apropriaram dessa área, na busca de validação para crenças religiosas e para práticas alternativas ou complementares no tratamento de saúde física e mental (MACHADO, 1996). Apesar disso, as origens da perspectiva da Psicologia Anomalística remontam à própria produção da Psychical Research (Pesquisa Psíquica), que precedeu a Parapsicologia. A Pesquisa Psíquica surgiu nos anos 1880s, 
voltada à investigação dos chamados fenômenos espíritas (efeitos físicos anômalos e obtenção de informações sem a utilização de meios/recursos de comunicação convencionais) que estavam em alta e aqueciam as conversas nas altas rodas da sociedade da época. A Psicologia Anomalística tem aí suas raízes evidenciadas, uma vez que aqueles mesmos pesquisadores que buscavam desvendar supostos mecanismos paranormais precisavam definir metodologicamente os limites ou extensões da mente, considerando-se o interesse de fazer, de fato, uma investigação científica. Foi exatamente o exercício dessa tentativa de controle do "já conhecido" como sendo suficiente para explicar episódios supostamente paranormais, que permitiu a emergência tanto da Psicologia Anomalística quanto da Parapsicologia.

Sob o rótulo de "psicólogos anomalísticos" estão também os membros de comunidades céticas e ateístas. Tratam-se justamente de psicólogos que, quase por convicção (ou ato de fé?), defendem a inexistência de processos psicológicos heterodoxos. Esses são rotulados pelos parapsicólogos muitas vezes como "céticos de carteirinha" dada a militante atuação contra a aceitação de existência de "anomalias" na Psicologia, numa atitude que Machado (2009) denomina de "paranormofóbica” - isto é, de predisposição a rechaçar a priori tudo o que poderia envolver algum tipo de interação anômala entre o ser humano e o ambiente. Por outro lado, sob a denominação de "parapsicólogos", encontramos diferentes membros de comunidades religiosas; inclusive casos de alguns que - dadas suas convicções metafísicas - parecem prescindir de qualquer evidência empírica que ofereça robustez para a afirmação de existência de certas anomalias psicológicas, ainda que essas sejam aceitas justamente como meio de legitimar suas crenças doutrinárias específicas. Esses são atacados pelos "céticos de carteirinha" como religiosos disfarçados de cientistas dado seu pendor para a afirmação de uma transcendência perdida na religiosidade tradicional que, na modernidade, encontra seu locus de resistência e legitimação na ciência.

Como se vê, portanto, a disputa nessa seara já pressupõe um embate de perspectivas epistemológicas nas quais o papel da religiosidade e da irreligiosidade parece ser fundamental. Ambos os grupos disputam um discurso sobre um mesmo campo: o das alegações, experiências e crenças paranormais. Haveria por trás delas algo além ou aquém do que a Psicologia já estabeleceu como existente? 
A dicotomia apresentada acima, no entanto, não representa o único caminho dessa área. Paradoxalmente, ao longo do último século e meio de estudos sistemáticos nesse campo, acompanhamos inversões de posicionamentos: há parapsicólogos que parecem ter se convencido de que os resultados de seus estudos não exigiriam explicações chamadas por Zangari (2005) de "paranormófilas" - ou seja, que pendem sempre para a busca de algum tipo de ação/evento paranormal para quaisquer eventos que ocorram; e, igualmente, há casos de "céticos de carteirinha" que parecem ter se surpreendido com a impossibilidade de oferecer explicações convencionais para os efeitos obtidos em seus estudos. Além disso, surgiram novos pesquisadores sem a mesma agenda pró ou contra "fenômenos parapsicológicos" que caracterizou um longo período de disputas nessa área. Talvez tenha sido um clima de real incerteza quanto a como interpretar as experiências alegadamente anômalas que esteja transformando o campo. Talvez, aliado a isso, haja o reconhecimento de que mais importante do que manter uma posição favorável ou desfavorável à existência de "fenômenos parapsicológicos autênticos" seja buscar compreender o que tais experiências, alegações e crenças nos permitem conhecer de seus experienciadores e como tais experiências impactam suas vidas e seus grupos.

É justamente essa última perspectiva que tem inspirado a criação de grupos de pesquisadores no exterior e no Brasil e que tem levado a uma produção sui generis no campo das experiências anômalas. O que deve ser afirmado é que tal produção apresenta uma característica nítida que deve ser ressaltada: sua importância para três campos ou para os campos interessados em cada uma das três facetas das experiências anômalas: (1) sua relação com a religiosidade; (2) sua aparente "inexplicabilidade" em termos psicológicos; e (3) sua dimensão mais prosaica ou psicológica convencional. Diante disso, fica evidente a importância desse campo para a Psicologia da Religião, para a Parapsicologia e para a Psicologia Anomalística "cética". Sob certa perspectiva é defensável, a rigor, que o conceito de experiências anômalas inclua as experiências religiosas.

A seguir, será enfatizada exclusivamente a relação entre experiências anômalas e experiências religiosas à luz das pesquisas recentes em Psicologia Anomalística em alguns âmbitos. 


\section{Estudos de experiências anômalas extramotoras e extrassensoriais}

Relatos de experiências que envolvem a suposta interação anômala com o ambiente (extramotora) e entre mentes (extrassensorial), isto é, sem a intermediação de mecanismos conhecidos, trazem consigo, na maioria dos casos, uma tentativa de compreensão das experiências, esta que pertence ao domínio das explicações religiosas. Vivências reconhecidas como sendo de tipo "telepático", "precognitivo" ou "psicocinético" são desafiadoras e conclamam a busca de explicações que aquietem a turbulência causada pela subversão da ordem natural de como as coisas acontecem ou se supõe acontecerem - como saber antecipadamente, sem qualquer meio convencional, o que ocorrerá no futuro, por exemplo. Essas experiências demandam explicações em termos causais que justifiquem suas ocorrências. $\mathrm{O}$ aspecto perturbador dessas experiências que desafiam a ordem espaço-temporal "estabelecida" pode implicar na adoção ou revisão de crenças de modo a dar conta de preencher o vazio de sentido ao qual, num primeiro momento, o experienciador é atirado.

Em seu estudo da prevalência e relevância das experiências anômalas de tipo extrassensoriomotor numa amostra de população brasileira, Machado (2010) verificou que, apesar de não haver diferenças estatisticamente significantes no nível de religiosidade entre pessoas que relatam experiências anômalas (experienciadores) e que não relatam tais tipos de experiências (não experienciadores), os experienciadores mostram-se mais inclinados a certos tipos de crença - como a crença na reencarnação, por exemplo - do que os não experienciadores. A abertura à possibilidade de transcender os limites humanos conhecidos e a crenças que extrapolem a realidade material que nos cerca parece facilitar a vivência desse tipo de experiência ou, no mínimo, focar a atenção para acontecimentos cotidianos com um olhar simpático a explicações de cunho sobrenaturalista.

Dentre os 306 participantes do estudo de Machado (2010), 82,7\% $(\mathrm{N}=253)$ relataram ao menos um tipo de experiência anômala extrassensorial ou extramotora. Dentre esses, $20 \%$ apontou a religião como recurso importante para lidar com episódios de experiências anômalas, especialmente os respondentes evangélicos e os espíritas kardecistas (MACHADO, 2009, p. 177-178). Isto vai ao encontro das atribuições de 
causalidade feitas pelos participantes, considerando as causas que atribuíam às vivências anômalas apontadas. De modo geral, as atribuições foram compatíveis com a indicação de pertença religiosa, crença ou adoção de filosofia de vida - por exemplo, evangélicos atribuíram suas experiências mais a Deus ou ao demônio do que respondentes sem religião ou ateus. Nas palavras de Machado:

A escolha de uma atribuição de causalidade religiosa... depende de uma predisposição do experienciador para interpretações religiosas e de um repertório ou vocabulário religioso. Todos temos acesso a informações sobre sistemas religiosos, e os conhecemos pelo menos até certo ponto. Mas, embora explicações religiosas sejam acessíveis, nem todos explicam tudo em termos religiosos. Faz diferença o peso que se dá a cada uma das explicações disponíveis. [...] a imagem daquilo ou daqueles a quem são feitas as atribuições são fundamentais na medida em que estão ligadas à construção de sentidos ao longo da vida, sentidos esses que se refletem na linguagem dos sujeitos. A escolha de uma atribuição religiosa ou "naturalista", de uma explicação de base afetiva ou racional vai depender do contexto cultural e de diferenças individuais (MACHADO, 2009, p. 252).

No entanto, no estudo mencionado houve não crentes que fizeram atribuições sobrenaturalistas e pessoas religiosas que fizeram atribuições naturalistas às suas vivências anômalas. E, além da tomada de decisões, especialmente crenças e atitudes foram influenciadas por essas vivências, em consonância com as expectativas e atribuições de cunho religioso ou sobrenaturalista feita a cada experiência específica. Pessoas disseram ter adotado ou mudado de religião em decorrência de suas experiências anômalas. Isto mostra como essas vivências são poderosas em termos de força transformadora do ser, de comportamentos e do direcionamento/sentido da vida. Deste modo, o estudo mostrou que a religiosidade que permeia o cotidiano de quem vivencia uma experiência anômala desempenha, via de regra, papel fundamental na atribuição e causalidade e de sentido para a experiência, assim como delineia, ao mesmo tempo, seus contornos. Outros estudos como este (eg.,TORRES, 2016; REICHOW, in progress) têm sido realizados e contribuído para esclarecer o impacto das experiências anômalas na religiosidade e vice-versa, mostrando-se úteis para aprofundamento de questões levantadas nos estudos especificamente da área da Psicologia 
da Religião que visa, em última instância, conhecer o comportamento religioso. Apesar das populações investigadas não serem grandemente numerosas, esses estudos mostram tendências que se inclinam à demonstração de como há confluência de aspectos religiosos, ascendendo sobre as experiências anômalas ocorridas no cotidiano, especialmente o autorrelato evidencia esse aspecto, uma vez que a indicação da experiência vem muito comumente acompanhada de uma atribuição religiosa. Nesse sentido, podemos dizer que, tomando como referência o ponto de vista do experienciador, toda experiência anômala pode ser considerada como religiosa, se aquele(a) que a vivencia a interpreta como tal.

\section{Estudos da mediunidade}

A mediunidade é um caso que parece ser exemplar, como fenômeno cujo estudo se situa entre as áreas da Psicologia da Religião e da Psicologia Anomalística. Apresenta, ao mesmo tempo, as dimensões de aparente anomalia e de experiência religiosa e, ainda, permite avaliações tanto dos indivíduos que a manifestam quanto dos grupos em que é praticada.

Esse caráter especial foi notado desde o início dos estudos sistemáticos da mediunidade e o impacto desses estudos sobre o conhecimento psiquiátrico e psicológico no final do século XIX e na primeira metade do século XX tem sido considerado como importante fonte de constructos psicológicos (ALVARADO et al., 2007). No Brasil, apesar de o fenômeno da mediunidade ser tão prevalente no contexto religioso, apenas recentemente a Psicologia, notadamente a Psicologia Anomalística, tem se dedicado ao seu estudo sistemático, ainda que seja possível encontrar referências a estudos ao longo do século XX (ZANGARI, 2001). Atualmente, têm sido realizados estudos da mediunidade em várias de suas dimensões, como a dimensão cognitiva, de personalidade (e.g.,: ZANGARI, 2005; ALMINHANA, MENEZES \& MOREIRAALMEIDA, 2013; MARALDI, 2014) e afetiva (e.g., MARALDI \& ZANGARI, 2012) dos médiuns, a dimensão psicossocial da mediunidade (e.g., ZANGARI \& MARALDI, 2009; MARALDI, MACHADO \& ZANGARI, 2010; MARALDI \& ZANGARI, 2012), a dimensão biopsicossocial (e.g., MARALDI \& KRIPPNER, 2013), a dimensão da saúde mental (e.g., MENEZES, ALMINHANA \& 
MOREIRA-ALMEIDA, 2012; ALMINHANA \& MOREIRA-ALMEIDA, 2014), a dimensão neurofisiológica (PERES et al, 2012) e a dimensão possivelmente anômala das experiências (RADIN, MACHADO \& ZANGARI, 2002; ZANGARI, 2007; ROCHA et al, 2014).

Dessa produção, pode-se destacar o quanto a mediunidade tem provocado a discussão acerca do diagnóstico diferencial entre desordens mentais e experiências anômalas. A mediunidade livrou-se do rótulo de doença mental e, mais que o resultado de processos dissociativos mórbidos, passou a ser compreendida como o resultado de um processo dissociativo normal e culturalmente disciplinado (MARALDI, MACHADO \& ZANGARI, 2010). Tal mudança de perspectiva nos remete, igualmente, aos critérios de diferenciação entre experiências religiosas patológicas e não patológicas, um tema que tem sido recorrentemente discutido na literatura (MARALDI, 2014; MENEZES, ALMINHANA \& MOREIRA-ALMEIDA, 2012; ALMINHANA \& MOREIRAALMEIDA, 2014). Manuais diagnósticos utilizados pelos profissionais de saúde mental, a exemplo do DSM-V (Diagnostic and Statistical Manual of Mental Disorders em sua quinta versão) fornecem indicações sobre como diferenciar experiências religiosas patológicas e não patológicas, e são sensíveis às classificações e interpretações culturais dessas experiências, como sugere a categoria de Problemas Religiosos e Espirituais (V62.89, Z65.8). O DSM-V também inclui critérios para o diagnóstico de transtorno de transe dissociativo, um tipo de manifestação dissociativa em que há perda de consciência e comportamentos estereotipados, a qual pode ser considerada patológica e envolver conteúdos de crença religiosa - por vezes associada a relatos de mediunidade e possessão - embora não integre necessariamente uma prática coletiva ou ritual religioso culturalmente sancionado (AMERICAN PSYCHIATRIC ASSOCIATION, 2013). Tais discussões exemplificam de modo claro a complexa interação entre experiências anômalas e interpretações e práticas religiosas, inclusive do ponto de vista de suas implicações para processos diagnósticos e psicoterapêuticos. $\mathrm{O}$ estudo de vivências anômalas/paranormais como a mediunidade pode iluminar, assim, determinados temas da literatura psiquiátrica e psicológica, como a dissociação, os quais, em contrapartida, possuem implicações para a compreensão de crenças e práticas religiosas a elas associadas. $\mathrm{O}$ estudo das experiências anômalas e da religião não estão, dessa forma, separados, mas interagem constantemente. 


\section{Estudos sobre alegados contatos com alienígenas}

Outro exemplo, entre muitos, de interseção entre experiências anômalas e religiosas são os alegados contatos com alienígenas. Especialmente a partir da segunda metade do século $\mathrm{XX}$, um número significativo e crescente de pessoas passou a reportar encontros de diversos tipos com objetos voadores não identificados (óvnis) e com entidades então compreendidas como alienígenas ou extraterrestres. Essas experiências subjetivas variam desde a simples visão de luzes no céu, as quais parecem não convencionais devido à sua aparência e comportamento, até interações complexas forçosas ou consentidas com alienígenas (cf. ampla revisão em MARTINS, 2015).

Um dos aspectos mais interessantes do estudo desses episódios para a Psicologia da Religião e para a Psicologia Anomalística é a caracterização propriamente contemporânea desses episódios, o que permite discutir, entre outros pontos relevantes e de vanguarda, a emergência de novas formas de religião e de espiritualidade.

Tais dimensões dessas experiências se manifestam de várias formas. Grupos com dezenas, centenas ou mesmo milhares de membros se organizam em torno do ícone "alienígena", não raro com propósitos e formatos religiosos, com ritos e sistemas de crença próprios que combinam religiões tradicionais e temas contemporâneos como ecologia, teorias conspiratórias de abrangência global, esoterismo "new age", ciência ficção científica (MARTINS, 2014; 2015).

Os alienígenas e óvnis tendem a cumprir, então, diversos papéis e funções tradicionalmente ligadas ao sobrenatural e ao divino, como fornecer sentido para a vida daqueles que os contatam, prometer salvação para a humanidade em períodos de crise planetária ou pessoal e ensinar caminhos espirituais (MARTINS, 2014). Eles tendem a ser vistos como misteriosos, perfeitos, transcendentes e sobrenaturais (MARTINS, 2015; SALIBA, 1995), além de arautos da morte tanto literal quanto simbólica, enquanto profunda transformação pessoal (MARTINS, 2011).

Figuras religiosas, mitológicas e folclóricas tradicionais como Cristo, deuses egípcios e nórdicos, o Boitatá e a Mãe do Ouro passam a ser compreendidos como alienígenas mal identificados no passado, o 
mesmo ocorrendo com passagens pontuais como a aparição de Deus no Monte Sinai (tratar-se-ia, frequentemente, da aparição de uma grande nave sobre o monte, trazendo ensinamentos de ordem civilizatória), a ascensão ao céu do profeta bíblico Elias (que teria sido, na verdade, sequestrado por alienígenas), as aparições dos veículos celestiais Vimanas, da mitologia indiana (que seriam naves espaciais), entre incontáveis exemplos (e.g., LEWIS, 1995).

\section{Outros estudos}

Outras modalidades de experiências anômalas têm sido estudadas com especial interesse dada sua imbricação com aspectos religiosos. Alguns estudos têm enfatizado a importância de se considerar certas experiências anômalas como muito próximas das experiências religiosas clássicas.

Ao estudar as experiências fora do corpo, Medeiros (2014), por exemplo, demonstra o quanto, para alguns experienciadores, tais vivências "se definem por seu alto teor espiritual/religioso, sendo muitas vezes entendida como mediunidade e trazendo, em diversas vezes, conteúdos morais, como sobre a necessidade da caridade ou mesmo entendendo a EFC como forma de praticar a caridade" (p. 45).

No âmbito do estudo das crenças paranormais, Paiva et al. (2012) demonstram que membros das religiões sincréticas e membros de religiões cristãs clássicas apresentaram padrões completamente diferentes quanto às crenças paranormais. O estudo levou em conta a diferenciação proposta por Rice (2003) entre "crenças paranormais clássicas" e "crenças paranormais religiosas”. Entre as primeiras estariam a crença em percepção extrassensorial, a crença em extraterrestres, no déjà vu e nas curas paranormais. Dentre as últimas estariam as crenças em deuses, no demônio, nos anjos, no céu, no inferno e na vida após a morte. Os resultados do estudo, à exemplo do estudo de Williams et al. (2009) que serviu-lhe de base, apontam para uma diferença clara de atitude entre grupos que mantêm crenças paranormais clássicas e que mantêm crenças paranormais religiosas tradicionais, de modo a ser possível distinguir a presença de cada classe de crenças 
paranormais de acordo com o perfil do grupo. A suposição inicial dos pesquisadores de que, em um meio cultural tão sincrético quanto o nosso, tanto os cristãos clássicos quanto os membros de religiões sincréticas adotariam indistintamente crenças paranormais em proporções sem diferenças significativas, não se demonstrou sustentável. Ainda que pareça correto afirmar que não exista correlação entre crenças paranormais e crenças religiosas tradicionais, o estudo apontou para a possível interferência de outro conjunto de crenças, a saber, a "espiritualista", como um fator modulador dos resultados da amostra de religiosos do grupo sincrético. Assim, foi possível demonstrar que a correlação entre crenças paranormais dependerá do sistema simbólico da religião investigada, de tal sorte que é possível prever que sistemas religiosos que incluem crenças espiritualistas (no sentido conferido ao termo Spiritualism pelos norte-americanos e europeus) tenderam a apresentar mais crenças paranormais clássicas que sistemas religiosos que não incluam tais crenças espiritualistas. Assim, tanto a presença ou ausência de crenças religiosas tradicionais, quanto a ausência ou presença de crenças espiritualistas devem ser considerados como moduladores dos resultados das amostras religiosas investigadas.

\section{Considerações finais}

A avaliação da produção recente em nosso meio, nas áreas da Psicologia da Religião e da Psicologia Anomalística, permite afirmar que esse campo, imbrincado dada a natureza aparentemente comum de seus objetos de estudo, tem feito contribuições significativas em vários aspectos tanto das experiências religiosas quanto das experiências anômalas.

Tais contribuições também ressaltam quão sutis e complexas podem ser as aproximações e tensões entre as variáveis e processos que permeiam experiências religiosas e anômalas. Dada a citada imbricação de seus objetos de estudo, é prejudicial à sua compreensão a desconsideração dessas sutilezas e das contribuições mútuas entre a Psicologia da Religião e a Anomalística. 


\section{Agradecimentos}

A segunda autora, pós-doutoranda do Programa de Estudos PósGraduados em Ciência da Religião da PUCSP agradece à Capes (Coordenação de Aperfeiçoamento de Pessoal de Nível Superior) a Bolsa PNPD a ela concedida. O terceiro e o quarto autores, pós-doutorandos do Programa de PósGraduação em Psicologia Social do Instituto de Psicologia da USP, agradecem à FAPESP (Fundação de Amparo à Pesquisa do Estado de São Paulo) as bolsas de pós-doutorado a eles concedidas.

\section{Referências}

ALMINHANA, L. O.; MOREIRA-ALMEIDA, A. Anomalous Experiences and Schizotypy: a necessary distinction between pathological and non-pathological psychotic experiences. Psyche \& Faith, v. 25, p. 127-134, 2014.

ALMINHANA, L. O.; MENEZES JR., A.; MOREIRA-ALMEIDA A. Personalidade, religiosidade e qualidade de vida em indivíduos que apresentam experiências anômalas em grupos religiosos. Jornal Brasileiro de Psiquiatria, v. 62, p. 268-274, 2013.

ALVARADO, C. S.; MACHADO, F. R.; ZANGARI W.; ZINGRONE N. L. Perspectivas históricas da influência da mediunidade na construção de ideias psicológicas e psiquiátricas. Revista de Psiquiatria Clínica, v. 34, p. 42-53, 2007.

AMERICAN PSYCHIATRIC ASSOCIATION. Diagnostic and Statistical Manual of Mental Disorders (DSM-V). Washington: American Psychiatric Publishing, 2013.

LEWIS, J. R. (Org.). The gods have landed: new religions from other worlds. Albany, NY: State University of New York Press, 1995.

MACHADO, F. R. A Causa dos Espíritos: Estudo sobre a utilização da Parapsicologia para a defesa da fé católica e espírita no Brasil. Dissertação (Mestrado em Ciências da Religião) - Pontifícia Universidade Católica de São Paulo, 1996.

MACHADO, F. R. Experiências Anômalas na Vida Cotidiana. Experiências extra-sensório-motoras e sua associação com crenças, atitudes e bem-estar subjetivo. Tese. (Doutorado em Psicologia) - Universidade de São Paulo, 2009. 
MACHADO, F. R. Experiências anômalas (extra-sensório-motoras) na vida cotidiana e sua associação com crenças, atitudes e bem-estar subjetivo. Boletim - Academia Paulista de Psicologia. n. 30, p. 462-483, 2010.

MARALDI, E. O. Medium or author? A preliminary model relating dissociation, paranormal belief systems and self-esteem. Journal of the Society for Psychical Research, v. 78, n. 1, p. 1-24, 2014.

MARALDI, E. O.; KRIPPNER, S. A Biopsychosocial Approach to Creative Dissociation: remarks on a case of mediumistic painting. NeuroQuantology, v. 11, p. 544-572, 2013.

MARALDI, E. O.; MACHADO, F. R.; ZANGARI, W. Importance of Psychosocial Approach for a Comprehensive Understanding of Mediumship. Journal of Scientific Exploration, v. 24, p. 181-196, 2010.

MARALDI, E. O.; ZANGARI W. Funções projetivas e terapêuticas das práticas dissociativas em contexto religioso. Boletim - Academia Paulista de Psicologia, v. 32, p. 424-452, 2012.

MARALDI, E. O.; ZANGARI, W. Individual and group dialectics in the study of mediumship: a psychosocial perspective. The Paranormal Review, v. 66, p. 14-18, 2013.

MARTINS, L. B. Imaginário, mito e o hades tecnológico. Junguiana, v. 29, p. 7-15, 2011.

MARTINS, L. B. Na trilha dos alienígenas: uma proposta psicológica integrativa sobre experiências "ufológicas" e "paranormais". 2015. Tese apresentada ao Programa de Pós-Graduação em Psicologia Social - Instituto de Psicologia da Universidade de São Paulo.

MARTINS, L. B. Naves espaciais, reencarnação e transmutação: a libertação do sofrimento em movimentos religiosos brasileiros contemporâneos. Interações: Cultura e Comunidade, v. 9, p. 330-349, 2014.

MARTINS, L. B.; Zangari, W. Relações entre experiências anômalas tipicamente contemporâneas, transtornos mentais e experiências espirituais. Revista de Psiquiatria Clínica, v. 39, p. 198-202, 2012.

MEDEIROS, G. T. de. Fenomenologia da Percepção Extracorpórea: Uma análise de comportamentos e crenças das experiências fora do corpo. 2014. Dissertação. (Mestrado em Ciências da Saúde) - Universidade Federal de São Paulo, São Paulo, 2014. 
MENEZES JR., A.; ALMINHANA, L.; MOREIRA-ALMEIDA, A. Perfil sociodemográfico e de experiências anômalas em indivíduos com vivências psicóticas e dissociativas em grupos religiosos. Revista de Psiquiatria Clínica, n. 39, p. 203-207, 2012.

PAIVA, G. et al., Verdade, M. M. Crença Paranormal Religiosa versus Crença Paranormal Clássica: um estudo transcultural. 2012. Relatório técnico à Capes (Edital MCT/CNPq/ MEC/CAPES N 02/2010), Processo 400716/2010-0.

PERES, J.; MOREIRA-ALMEIDA, A.; CAIXETA, L.; LEAO, F. C.; Newberg, A. Neuroimaging during Trance State: A Contribution to the Study of Dissociation. Plos One, 2012, 7, p. e49360.

RADIN, D.; MACHADO F. R.; ZANGARI W. Effects of Distant Healing Intention Through Time \& Space: Two Exploratory Studies. Subtle Energies And Energy Medicine Journal, v. 3, p. 207-240, 2002.

REICHOW, J. R. C. Experiências Anômalas em Diferentes Populações Brasileiras: Prevalência, relevância, diagnóstico diferencial de transtornos mentais e relação com qualidade de vida. Tese. (Doutorado em Psicologia Social) - Instituto de Psicologia da Universidade de São Paulo. (No prelo)

RICE, T. Believe it or not: Religious and other paranormal beliefs in the United States. Journal for the Scientific Study of Religion, v. 41, 95-106, 2003.

ROCHA, A. C.; PARANÁ, D.; FREIRE, E. S.; LOTUFO NETO, F.; MOREIRA-ALMEIDA, A. Investigating the Fit and Accuracy of Alleged Mediumistic Writing: A Case Study of Chico Xavier s Letters. Explore, v. 10, p. 300-308, 2014.

TORRES, C. M. Experiências Anômalas e Atribuição de Causalidade no Protestantismo Clássico Brasileiro. 2015. Tese de doutorado apresentada ao Programa de Pós Graduação em Psicologia Social do Instituto de Psicologia da Universidade de São Paulo, 2015.

SALIBA, J. A. Religious dimensions of UFO phenomena. In: Lewis, J. R. (Ed.) The gods have landed: new religions from other worlds. Albany, NY: State University of New York Press, p. 15-64, 1995. 
WILLIAMS, E.; F., L.; L., C. A. Introducing the Modified Paranormal Belief Scale: Distinguishing Between Classic Paranormal Beliefs, Religious Paranormal Beliefs and Conventional Religiosity Amnong Undergraduates in Northern Ireland and Wales. Archives for the Psychology of Religion, 31, 345-356, 2009.

ZANGARI, W. Estudos Psicológicos da Mediunidade: Uma breve revisão. Revista Virtual de Pesquisa Psi, São Paulo, 2001.

ZANGARI, W. Experiências Anômalas em Médiuns de Umbanda: uma avaliação fenomenológica e ontológica. Boletim-Academia Paulista de Psicologia, v. 2, p. 67-86, 2007.

ZANGARI, W. Uma leitura psicossocial do fenômeno de incorporação na Umbanda. Boletim-Academia Paulista de Psicologia, v. 3, n. 5, p. 70-88, 2005.

ZANGARI, W; MARALDI, E. O. Psicologia da Mediunidade: do intrapsíquico ao psicossocial. Boletim - Academia Paulista de Psicologia, n. 77, p. 233-252, 2009.

Recebido: 03/11/2016

Received: 11/03/2016

Aprovado: 06/01/2017

Approved: 01/06/2016 